\title{
Reconsidering the Loss of Evolutionary History: How Does Non-random Extinction Prune the Tree-of-Life?
}

\author{
Kowiyou Yessoufou and T. Jonathan Davies
}

\begin{abstract}
Analysing extinction within a phylogenetic framework may seem counter-intuitive because extinction is a priori a non-heritable trait. However, extinction risk is correlated with other traits, such as body size, that show a strong phylogenetic signal. Further, there has been much effort in identifying key traits important for diversification, and recent evidence has demonstrated that the processes of speciation and extinction may be inextricably linked. A phylogenetic approach also allows us to quantify the impact of extinction, for example, as the loss of branches from the tree-of-life. Early work suggested that extinctions might result in little loss of evolutionary history, but subsequent studies indicated that nonrandom extinctions might prune more of the evolutionary tree. Loss of phylogenetic diversity might have ecosystem consequences because functional differences between species tend to be correlated with the evolutionary distances between them. Here we explore how extinction prunes the tree-of-life. Our review indicates that the loss of evolutionary history under non-random extinction (the emerging pattern in extinction biology) might be less pronounced than some previous studies have suggested. However, the loss of functional diversity might still be large, depending on the evolutionary model of trait change. Under a punctuated model of evolution, in which trait differences accrue in bursts at speciation, the number of branches lost is more important than their summed lengths. We suggest that evolutionary models need to be incorporated more explicitly into measures of phylogenetic diversity if we are to use phylogeny as a proxy for functional diversity.
\end{abstract}

Keywords Extinction risk $\bullet$ Phylogenetic comparative methods $\bullet$ Punctuated evolution $\bullet$ Phylogenetic diversity $\bullet$ Feature diversity

\footnotetext{
K. Yessoufou

Department of Environmental Sciences, University of South Africa,

Florida, Gauteng, South Africa

e-mail: kowiyouyessoufou1@gmail.com

T.J. Davies $(\bowtie)$

Department of Biology, McGill University, Montréal, Québec, Canada

e-mail: j.davies@mcgill.ca 


\section{Introduction}

There is mounting evidence that we are entering a sixth mass extinction (Millennium Ecosystem Assessment 2005), and the future of biodiversity is at risk due to the high rates at which biological diversity - species, habitats, evolutionary diversity is being eroded. Species are experiencing unprecedented pressures across their ranges owing to global change, including increased invasion success of aliens (Winter et al. 2009), habitat destruction (Vitousek et al. 1997; Haberl et al. 2007), climate change and climate variability (Willis et al. 2008, 2010). Consequently, approximately $30 \%$ of assessed species are currently categorised as threatened by the IUCN, and a greater proportion may be committed to extinction in the near future (Thomas et al. 2004). Current rates of species loss might be 1,000-10,000 times greater than past extinction rates (Pimm et al. 1995; Millennium Ecosystem Assessment 2005) with particularly elevated rates in tropical biomes (Vamosi and Vamosi 2008), known for their unique life-form diversity. At the ecosystem level, with the loss of species, we also lose their contributions to overall ecosystem functioning and services. The loss of ecosystem services is of particular concern because human survival relies strongly on key services such as food production, plant pollination, medicinal plants, clean water, clean air, nutrient cycling, carbon sequestration, climate stability, recreation, tourism, etc. - which are provided by a well functioning system of biological diversity.

It is well established that human activities can drive extinctions within a short period of time (Baillie et al. 2004; Mace et al. 2005a). Because human population has increased exponentially over the last centuries, and is expected to reach nine billion by 2050 (www.un.org/esa/population/publications/longrange2/2004worldpo p2300reportfinalc.pdf), pressure on natural ecosystems is also predicted to increase, yet at the same time there will be an even greater demand for the ecosystem services provided by biologically diverse natural systems. As a result, the rate of species extinction is projected to rise by at least a further order of magnitude over the next few hundred years (Mace et al. 2005b), potentially decreasing the provisioning of ecosystem services at a time when demand is growing. Understanding how the ongoing extinction crisis will impact the provisioning of critical ecosystem services is therefore a matter of urgency.

Quantifying the ecosystem contributions of individual species is a major challenge. Current estimates of global diversity vary by over an order of magnitude (see e.g. May 2010), with the vast majority of species (86\% and $91 \%$ of terrestrial and oceanic diversity, respectively) remaining unknown to science (Mora et al. 2011). An in-depth understanding of species ecologies is therefore impractical for most of life; at best, we might be able to infer their placement on the tree-of-life. Whilst there is now a general consensus on the positive link between biodiversity and ecosystem function (Hooper et al. 2012), there has been growing evidence suggesting that evolutionary history provides a more informative measure of biological diversity than traditional metrics based upon richness and abundance (e.g. Faith 1992; Faith et al. 2010; Davies and Cadotte 2011; see also Srivastava et al. 2012 for a comprehensive review). It is suggested that evolutionary history might better capture 
functional diversity including unmeasured or hard-to-measure traits (Crozier 1997; Faith 2002). As such, phylogeny provides a unique framework that captures both known (Forest et al. 2007; Saslis-Lagoudakis et al. 2011) and unknown ecosystem services (Faith et al. 2010). Understanding how the current extinction crisis will prune the tree-of-life is therefore critical for ensuring a continued provisioning of the ecosystem services upon which we rely, but for which we might lack detailed ecological knowledge of underlying process or mechanism (Faith et al. 2010).

There has been growing effort to incorporate species evolutionary histories into conservation decision-making (e.g. Purvis et al. 2000a, 2005; Isaac et al. 2007, 2012; Faith 2008). This effort has been facilitated by the rapid rise in analytical tools, and the availability of large comprehensive phylogenetic trees for well studied taxonomic groups such as mammals (Bininda-Edmonds et al. 2007), birds (McCormack et al. 2013), amphibians (Pyron and Wiens 2013), and flowering plants (e.g. Davies et al. 2004). Here, we review recent insights from phylogenetic studies of extinction risk, and re-examine how extinctions impact the tree-of-life.

\section{Speciation and Extinction as Two Natural Processes}

Extant species represent just a small fraction of all the species that have ever lived (Jablonski 1995; May et al. 1995; Niklas 1997). This standing biodiversity is the net difference between cumulative speciation and extinction over the evolutionary history of life on Earth. Both the processes of speciation and extinction are therefore intrinsic parts of Earth's natural history. Much effort has gone into exploring geographic and taxonomic patterns of diversity, looking to answer why some regions and some taxa are more species-rich than others. Recent debate has contrasted explanations based upon ecological limits and times for speciation (e.g. see Rabosky and Lovette 2008). Comparisons between sister taxa, which are by definition of equal age, allow us to control for time for speciation, and thus differences in richness must reflect either variation in speciation or extinction rates (Barraclough et al. 1998). Such comparisons have shown that diversification rates have been higher in more tropical lineages (Davies et al. 2004; Rolland et al. 2014), but that higher tropical species richness is most likely a product of both faster rates and longer times for speciation (Jansson and Davies 2008). However, high diversification might be explained by high speciation rates, low extinction rates or a combination of both, and until recently, it has not been possible to reliably disentangle the two.

Unraveling the processes of extinction and speciation remains a major challenge (Benton and Emerson 2007). The fossil record is often thought to provide the most reliable documentation of speciation and extinction, yet the cumulative fossil record suggests that speciation rate increases inexorably through time (Raup 1991; Nee 2006; Benton and Emerson 2007), whereas there is growing evidence suggesting that species accumulate in bursts, and speciation rates decline over time (Simpson 1953; Schluter 2000; Gavrilets and Vose 2005; Scantlebury 2013). Phylogeny provides an alternative tool for reconstructing evolutionary process (Harvey et al. 
1994). Nee et al. (1994) illustrated how extinction rates could be estimated from phylogenetic trees (but see Rabosky 2010), but assumed constant rates model. New methods, for example, BiSSE (Maddison et al. 2007) and GeoSSE (Goldberg et al. 2011), relax this assumption, and allow us to estimate extinction and speciation rates simultaneously, for example, with the gain or loss of particular character states (BiSSE) or shifts in geographic distributions (GeoSSE). Phylogeny-based analysis of diversification provides some limited evidence for increasing speciation through time (e.g. Barraclough and Vogler 2002; Linder et al. 2003; Turgeon et al. 2005), but again, a scenario of rapid radiation followed by a decline in speciation rate over time appears to be more common (Harmon et al. 2003; Shaw et al. 2003; Kadereit et al. 2004; Machordom and Macpherson 2004; Morrison et al. 2004; Williams and Reid 2004; Xiang et al. 2005; Kozak et al. 2006; Weir 2006; Phillimore and Price 2008; Scantlebury 2013). This pattern could be linked to a density-dependent model of ecological opportunity and/or reflect punctual mass extinctions (e.g. Yessoufou et al. 2014) that open up new niche space for subsequent radiations (Crisp and Crook 2009). Recently, using phylogenetic information on the Cape Floristic Region, Davies et al. (2011) suggested that the processes of speciation and extinction may be inextricably linked.

Speciation and extinction are part of life's natural history, and to achieve equilibrium in standing diversity, speciation must equal extinction (Raup 1986). Even the classic MacArthur and Wilson $(1963,1967)$ model of island biogeography suggests that species richness is a dynamic equilibrium between immigration, speciation and extinction. However, today this balance is increasingly biased towards extinction (Millennium Ecosystem Assessment 2005), and we risk moving towards a new lowdiversity state as it is not possible to manipulate speciation rates to match current losses (Barraclough and Davies 2005). Whilst there is increasing evidence that evolutionary processes can occur over ecological time scales (Kettlewell 1972; Endler 1986; Kinnison and Hendry 2001; Ashley et al. 2003), speciation can take a longer time to complete, whereas extinctions are occurring over much shorter time spans (Barraclough and Davies 2005). Even for the most famous examples of rapid speciation, such as Lake Victoria cichlids, diversification rates are estimated over 100's to 1000's of years, and evidence of 'reverse-speciation' indicates that speciation might not have been complete (Seehausen 2006). By contrast, rates of extinction are now estimated at many times background rates (Vitousek et al. 1997; Butchart et al. 2004), and are occurring over 10's to 100's of years.

\section{Shifting the Balance Towards a Low-Diversity Earth}

\section{Extinction Trends}

Whilst the scale of current species loss parallels that of mass extinction events in the paleontological past (May et al. 1995; Millennium Ecosystem Assessment 2005), unlike past extinctions which were caused by abiotic factors such as asteroid strikes, 
volcanic eruptions, and natural climate shifts, the current crisis is driven largely by human activities, and is perhaps the first mass extinction event that can be attributed to a biotic cause. Current estimates indicate that $10-30 \%$ of mammals, amphibians and birds are threatened with extinction (Millennium Ecosystem Assessment 2005). Taxonomic groups are not, however, equally at risk of extinction. Among terrestrial vertebrates, amphibians have the highest proportion at at-risk species, with at least a third of $\sim 6600$ known amphibians threatened with extinction (Wake and Vredenburg 2008). It is estimated that $12 \%$ and $20 \%$ of continental birds and mammals, respectively, have already been lost (Wilson 1992), but with a higher rate of loss observed on islands (Lohle and Eschenbach 2011). In fish, of the 2,000 species that have been assessed $21 \%$ are considered at risk of extinction (IUCN 2010). Our knowledge of extinction risks in invertebrates is much poorer; however, of the 1.3 million known invertebrates, less than 10,000 species have been assessed, of which $30 \%$ are threatened (IUCN 2010).

In plants, extinction trends appear to be even more alarming, but estimates need to be interpreted carefully. For example, over $70 \%$ of Red-listed species of flowering plants are classified as at risk of extinction (category VU or higher) (IUCN 2010). This proportion is much higher than that reported for vertebrate groups ( $22 \%)$, but as yet only a very small fraction of total plant diversity has been assessed ( 13,000 of $>300,000$ species), and a trend towards focusing on some of the most obviously vulnerable species might bias our estimates of threat upwards. For clades with more complete sampling, such as cycads, the proportion of threatened species remains high $(>80 \%)$, but perhaps this ancient group that peaked in diversity in the Jurassic-Cretaceous (Jones 2002; Taylor et al. 2009) when dinosaurs roamed the Earth, is not representative of current seed plant diversity. One recent attempt to estimate the true proportion of threatened species within angiosperms using a statistical model to correct for sampling bias - the sampled Red List - has suggested that the percent of at-risk plant species might actually be more comparable to that for mammals (http://threatenedplants.myspecies.info/).

The spatial congruence in taxonomic richness across taxonomic groups has been well described globally (Grenyer et al. 2006), with the richest areas of the world found in highly productive environments at low latitudes and in mountainous regions (Orme et al. 2005). Similarly, there is a geographical pattern in the distribution of rare and threatened taxa, which has been shown at the global scale for vertebrates (e.g. Grenyer et al. 2006), and at various scales for plants (e.g. Zhang and Ma 2008; Davies et al. 2011; Daru et al. 2013). However, hotspots of richness and rarity or threat do not necessarily coincide (Grenyer et al. 2006). For example, vertebrate richness peaks on the Neotropical mainland, but bird rarity concentrates on oceanic island archipelagos, the diversity of rare mammal species peaks on continental shelf islands and rare amphibian species are more centered on continental landmasses (Grenyer et al. 2006). The variation in geographical patterns of rarity may be partially linked to differences in relative dispersal ability across taxa. Spatial variation in extinction risk additionally reflects differences in the distribution of threats facing each group. For example, invasive species and overexploitation are key threats for birds whereas overexploitation is the major driver of species loss in mammals 
(Baillie et al. 2004), and climate change, pollution and transmissible diseases are important in amphibians (Stuart et al. 2004).

\section{Extinction Drivers: Animals Versus Plants}

\section{Extrinsic Versus Intrinsic Factors}

Explaining why some species appear predisposed to higher extinction risk than others is an important goal for conservation research (McKinney 1997). The five main extinction drivers include habitat loss, climate change, increased pollution, resources over-exploitation and invasive species (Millennium Ecosystem Assessment 2005), and all are linked directly or indirectly to anthropogenic pressures. These drivers parallel Jarred Diamond's 'evil quartet' (Diamond 1984, 1989), but with the more recent addition of climate change, and Diamond additionally included the possibility of extinction cascades in which secondary extinctions follow the loss of key species, for example, due to the disruption of ecosystem processes. We can further simplify this list into extrinsic (e.g. climate change) and intrinsic factors (e.g. ecological traits such as population density and species life-history traits such as body size and gestation length) (Cardillo et al. 2005). Extrinsic factors might help explain geographic variation in extinction risk, whereas intrinsic factors might better explain taxonomic patterns; however, highest risk is where driver intensity associated with extrinsic factors overlaps with species intrinsic vulnerability. In addition, species are increasingly likely to be exposed to multiple drivers, and this will likely further exacerbate risk of extinction (Brook et al. 2008).

\section{Extinction Drivers in Animals}

Correlates of extinction risk in animal kingdom have been explored extensively using data from the IUCN Red List (Bennett and Owens 1997; Russell et al. 1998; Purvis et al. 2000a, b; Cardillo 2003; Cooper et al. 2008) with particular attention to mammals (Russell et al. 1998; Cardillo et al. 2005, 2008; Isaac et al. 2007; Huang et al. 2012), perhaps the best-studied higher taxonomic group. Across studies, high extinction risk is generally associated with large body size, long generation times and small geographic range sizes (Bennett and Owens 1997; Russell et al. 1998; Purvis et al. 2000a; Cardillo 2003; Fisher and Owens 2004; Cooper et al. 2008). Conversely, species at low risk of extinction are small, reproduce rapidly, and have a wide niche breadth.

We know, for example, that mammals that are at risk of extinction are, on average, an order of magnitude heavier than non-threatened species (IUCN 2003). The size-selectivity of extinction risk is not unique to the current extinction crisis; past mass extinction events, such as that of the late Pleistocene, were also biased towards larger species (Martin 1967; Johnson 2002). During the late-Pleistocene - early- 
Holocene extinction event, there was a mass extinction of much of the mammalian megafauna, resulting in a loss of several complete ecological guilds and their predators (Cione et al. 2003). Size selectivity in extinction risk has been long-recognised (e.g. Pimm 1991; Lawton 1995; Pimm et al. 1988; Cardillo and Bromham 2001; Johnson 2002), and there are many potential explanations. Large-sized mammals might be more extinction-prone because of generally lower average population densities (Damuth 1981), putting them at greater risk from stochastic population dynamics. High risk in large bodied mammals might also reflect the negative correlation between intrinsic rates of population increase and body mass (Fenschel 1974), and thus longer recovery times following population declines. There might also be an increased propensity for humans to exploit larger species (Bodmer et al. 1997; Jerozolimski and Peres 2003). The relationship between species traits and extinction risk, however, is not straightforward, because of the complex interaction between intrinsic and extrinsic drivers, and different clades might have very different predictors (e.g. see Cardillo et al. 2008).

Cardillo and colleagues (2005) demonstrated that risk in small-sized mammals $(<3 \mathrm{~kg})$ was largely determined by extrinsic factors including the size and location of geographical ranges. However, the predisposing factors in the larger size class include both intrinsic species properties (e.g. population density, neonatal mass and litters per year) and extrinsic factors. Such fine-scaled analyses can help address whether extinctions are linked to 'bad genes' or 'bad luck' (Raup 1993; Bennett and Owens 1997). For mammals, it appears that extinction in small bodied species is more likely a case of bad luck, driven by extrinsic factors. For larger bodied species, bad genes, that is, genes controlling intrinsic traits such as body size and life history are additional aggravating factors promoting extinctions.

Compared to vertebrates, the distribution and drivers of extinction risk in invertebrate communities has been poorly explored. However, a recent study estimated that one-fifth of invertebrate species may be threatened with extinction, with freshwater species at particular high risk (Collen et al. 2012). Collen and colleagues suggested that the greater threat to freshwater species was predominantly driven by agricultural pollution and dam construction, invasive species and waterborne diseases. More generally, and perhaps unsurprisingly, species that are less mobile and with limited geographic ranges, such as freshwater mollusks, tend to be at higher risk (Collen et al. 2012). In marine ecosystems, however, the market values of some invertebrates correlate strongly with their risk of extinction, e.g. invertebrate species considered luxury seafood (Purcell et al. 2014), providing an exception to the general trend for greater threat to be observed in larger-sized species.

The phylogenetic distribution of extinction risk in mammals has also been of much interest. In mammals, it has been suggested that species subtending from longer phylogenetic branches, and thus representing greater unique evolutionary history, are at higher risk of extinction (Russell et al. 1998; Purvis et al. 2000a). This pattern matches to Wilson's (1961) 'taxon cycle', which predicts that older species would have higher extinction probabilities as species expand and contract in their geographical distributions over their evolutionary lifetimes. Although, as originally described, the taxon cycle referred to the distribution of species on islands (ants on 
islands in Melanesia), the concept has been extended to include species on continents (e.g. see Ricklefs and Bermingham 2002). Alternatively, it might simply echo the pattern of historical extinctions, in which older species represent survivors of once more diverse clades (Purvis et al. 2000a). However, the precise relationship between extinction risk and evolutionary age remains debated (Verde et al. 2013). Further, patterns of extinction risk in plants appears to show an opposite trend, with higher risk associated with young species in species rich (Schwartz and Simberloff 2001; Meijaard et al. 2007) and more rapidly diversifying clades (Davies et al. 2011), suggesting that predictors of extinction in plants might be very different to those for mammals.

\section{Extinction Drivers in Plants}

Species extinction in the plant kingdom is predominantly the result of habitat loss, for example through deforestation. Tropical forests, which cover less than $7 \%$ of the world land area, contain over $50 \%$ of global biodiversity (Dirzo and Raven 2003), but these unique habitats are being destroyed at unprecedented rates (Laurance 1991; Achard et al. 2002) as a result of rapid human population growth and economic development. In tropical Asia and Africa, over $40 \%$ of the primary forests is already lost (Wright 2005). This drastic reduction in forest cover has had a devastating impact on plant diversity (Sodhi and Brook 2006). Although there is some evidence that, globally, recent rates of deforestation are slowing, we likely owe a large extinction debt due to the time lag between habitat loss and species losses predicted from the reduction in area. Thus, even should we be successful in preserving the remaining forest cover, many species might still be predicted to be lost over the following decades as habitats return to a new, lower diversity, equilibrium state. This extinction event will likely be exacerbated by the effects of ongoing climate change as local climate conditions shift and species are forced to either adapt to new conditions or track climate space (Willis et al. 2008).

Plant responses to environmental change are difficult to predict. With warming, plants might adapt by shifting their phenologies - the timing of life history strategies - for example flowering earlier and losing leaves later (Parmesan 2007). Recent work indicates significant phylogenetic conservatism in flowering phenology (Davies et al. 2013), suggesting that there might be some evolutionary constraints to species adaptive responses. If the velocity of climate change is high, species may not have the necessary time to adjust their phenological responses. Alternatively, species might track suitable climates, for example by shifting their distribution northwards or towards higher elevations (Sandel et al. 2011). Species already restricted to high elevation biomes might then be particularly vulnerable as increased warming may result in the reduction of suitable habitat and, at the extremes, complete habitat loss. In the biodiversity hotspots of the Eastern Arc Mountains of East 
Africa, species at higher elevations already tend to be more threatened, perhaps reflecting recent climate shifts (Yessoufou et al. 2012). Species that are unable to adapt their phenology or track climate through space will be most vulnerable to extinction. In data from Thoreau's woods in Concord, MA, spanning 100 years, it is already possible to detect declines in populations among species that have failed to shift their phenologies to match recent climate change (Willis et al. 2008, 2010). These data also revealed phylogenetic structure in species responses, suggesting evolutionary conservatism not only in flowering times, but also plasticity in flowering times (see also Davies et al. 2013).

As for animals, there has been much work aimed at identifying intrinsic lifehistory traits that predispose some plant species towards extinction (Sodhi et al. 2008). However, investigating the correlates of extinction risk within the plant kingdom has proven somewhat more challenging, as key traits frequently differ between studies (Walker and Preston 2006; Sodhi et al. 2008). In addition, traits explain only a small proportion of the variation in extinction risk and, with the exception of geographic range size, we have yet to reveal any single strong correlate equivalent to, for example, body size in mammals. Life-history traits that have been found to correlate with plant extinction include pollination syndrome (e.g. wind or animal mediated), sexual system, habit, height, and dispersal mode (Sodhi et al. 2008). For tropical angiosperms, these traits can explain $\sim 10 \%$ of extinction risk (Sodhi et al. 2008), whereas equivalent models of intrinsic drivers for mammals can explain up to $30 \%$ of the variation in extinction risk (Cardillo et al. 2008). However, even for mammals, explanatory power tends to be lower when exploring predictors across disparate clades (Cardillo et al. 2008), reflecting clade specific sensitivities to different drivers. Perhaps, therefore, it is unsurprising that in flowering plants, a group containing up to 500,000 species, predictive models are often poor.

An alternative avenue of exploration has considered the importance of evolutionary history in models of extinction risk (Sodhi et al. 2008; Davies et al. 2011). In plants, there is increasing evidence that a species evolutionary history might be more important than its life history in explaining extinction risk. As mentioned above, threatened terrestrial plants generally fall within species-rich clades (Schwartz and Simberloff 2001; Pilgrim et al. 2004) that represent recent radiations (Davies et al. 2011). However, when we look at the distribution of extinction risks across plant families, species-poor and especially monotypic families also appear to contain species at higher risk of extinction (Vamosi and Wilson 2008). It is therefore possible that mechanistic explanations for variation in extinction risk differ between old and young clades. Old and species-poor families may represent remnants of once more diverse clades, with species vulnerabilities associated with intrinsic life history traits and long generation times, as in mammals. In contrast, extinction risk in younger, still diversifying clades, may be more closely linked to the speciation process, with high extinction risk more closely associated with traits driving speciation, such as small geographic range size and short generation times. 


\section{The Importance of Phylogeny in Conservation}

\section{Why We Need to Evaluate Extinction Risk within a Phylogenetic Framework}

Phylogenetic approaches are now well accepted in many ecological disciplines. Phylogenetic methods are also increasingly commonplace in extinction biology (see Purvis 2008). The necessity of employing a phylogenetic framework for exploring a non-evolving trait such as risk of extinction has been questioned (Grandcolas et al. 2011). Reasons for doing so are multifold. First, as we have discussed above, many drivers of extinction risks can be linked to phylogenetically conserved traits, such as body mass (Cardillo et al. 2005, 2008) and phenology (Willis et al. 2008, 2010). Therefore, phylogenetic comparative methods, such as independent contrasts (Felsenstein 1985) or phylogenetic regression are important because species cannot be considered as statistically independent (see Purvis 2008 for further discussion). Second, species evolutionary history might itself be an important predictor of extinction risk, for example, with higher risks associated with either more evolutionarily distinct lineages (Purvis et al. 2000a; Mace et al. 2003) or centres of diversification (Davies et al. 2011), depending on the clade and taxonomic scale. Third, by considering extinction within a phylogenetic framework, we can quantify directly its impacts on the tree-of-life as the loss of phylogenetic diversity (PD) (Purvis et al. 2000a; Mace et al. 2003). This measure of evolutionary heritage provides a useful conservation metric, typically measured in millions of years, it is easily comprehendible, and simple to calculate for particular regions or taxa (Mooers et al. 2005). Although, there remain practical obstacles in the implementation of phylogenetic approaches for conservation planning, there is now increasing appreciation of the importance of including an evolutionary perspective within conservation goals, as illustrated by the Zoological Society of London's EDGE of existence programme (http://www.edgeofexistence.org/) that emphasises the conservation of evolutionary distinct and threatened species (Isaac et al. 2007).

\section{Practical Contribution of Phylogeny to Conservation}

The practical contribution of phylogeny to conservation actions has recently been discussed (Cardillo and Meijaard 2012; Winter et al. 2013). In part, the conservation value of the phylogenetic approach is in its ability to guide pre-emptive actions towards identifying and prioritizing the most at-risk species. For example, by identifying species with traits or in regions that predispose them to high risk of extinction, we can identify species that are not yet at risk of extinction but which might become threatened in the near future if current extinction drivers increase in intensity or geographic extent. Cardillo et al. (2006) referred to such species as having high 'latent risk' of extinction. Given limited conservation funding, focusing efforts on species with high latent risk might make economic sense as it is likely to be more 
cost effective to prevent species declines before they begin versus reestablishing viable populations for species that have already suffered declines and may have lost much of their natural range. Preserving intact habitats will almost always be easier and cheaper than returning transformed habitats to their natural states.

A justification for placing emphasis on the preservation of phylogenetic diversity per se is that phylogenetic diversity captures feature diversity (Faith 1992; Crozier 1997; see also section "Feature diversity and evolutionary models of character change"), and thus preserving the set of species that maximizes phylogenetic diversity also maximizes the possibility of having the right set of features in an uncertain future. Forest et al. (2007) provided an example of the utility of phylogenetic diversity in the Cape Floristic Region of South Africa by demonstrating that preserving the phylogenetic diversity of the flora would maximize future options for the benefit of society through a continued provisioning of key ecosystem services. To date, empirical examples of conservation actions implemented explicitly to protect phylogenetic diversity are rare; however, one recent effort spearheaded by the Zoological Society of London's EDGE programme specifically aims at focusing conservation attention on evolutionary distinct species at risk of extinction. These EDGE species are distinct not only in the history of their evolutionary past, but perhaps also in the functional roles they might fill within ecosystems. The extinction of EDGE species might therefore result in the loss of important ecosystem functions and services for which we have no species substitute. Some EDGE species (e.g. elephants and pandas) are well known, but many others (e.g. Chinese giant salamanders and the peculiar long-beaked echidnas) have been overlooked by traditional conservation strategies (see Isaac et al. 2007, 2012).

Critically, the utility of phylogenetic metrics and methods in conservation biology relies upon the accuracy of the underlying phylogenetic topology and, if we are interested in capturing feature diversity, the evolutionary model of character change along the branches of the tree, a point we explore further in the following sections.

\section{Extinction and the Loss of Evolutionary History}

\section{Phylogenetic Structure in Extinction Risks}

We have discussed above how the process of extinction is non-random with respect to species traits and geography. For example, extinction will tend to remove largebodied species with slow life histories and narrow niches, and species in regions with high intensity of extinction drivers. Because many of the traits linked to extinction risk (e.g. body size, generation time, dispersal ability etc.) demonstrate phylogenetic conservatism (Fritz and Purvis 2010), such that they tend to be clustered on the phylogeny, extinctions will also tend to cluster on the phylogeny. Whereas evidence for trait-based explanations for plant extinctions is mixed (Freville et al. 2007; Bradshaw et al. 2008; Sodhi et al. 2008; Davies et al. 2011; Daru et al. 2013), 
phylogenetic selectivity in extinction risk might also result from a geographical pattern in the drivers of extinction, for example, range elevation might determine a species vulnerability to climate change (Sandel et al. 2011). If closely related species also tend to have close geographical proximities, perhaps reflecting shared habitat preferences or the geographical process of speciation, they will then also be exposed to similar intensity of extinction drivers. There is an increasing weight of evidence suggesting that extinction risk is generally more clustered on a phylogeny than expected by chance (Bennett and Owens 1997; Purvis et al. 2000a; Schwartz and Simberloff 2001), a pattern also observed within the fossil record. Extinction will thus prune the tree-of-life non-randomly. However, how this non-random pruning might impact the loss of evolutionary history has been a subject of recent debate.

\section{Quantifying the Loss of Evolutionary History}

Extinction prunes species from the tips of the tree-of-life, resulting in the loss of terminal branches. In a frequently cited paper, Nee and May (1997) used simulations to explore the expected loss of evolutionary history (quantified as the summed branch lengths from the tree-of-life) under various extinction intensities. Perhaps surprisingly, they found that up to $80 \%$ of the tree would remain under even extreme extinction scenarios in which $95 \%$ of species were lost. However, their simulations were unrealistic in two regards. First, they assumed extinction events were random - the field-of-bullets model, in which extinction is independent of species' traits and thus also phylogeny. If extinctions are clustered on a phylogeny, we might also lose the internal branches of the tree that connect them, and thus experience a greater overall loss of phylogenetic diversity (Russell et al. 1998; Purvis et al. 2000a). Second, their expectation was derived assuming a phylogeny based on a coalescent model, which generates a highly unrealistic distribution of branching times, with most branches clustered towards the present (see Fig. 1a), and does not fit to most empirical estimates of phylogenies. Importantly, coalescent trees tend to be 'tip-heavy' such that most branching events are short and clustered towards the present (tips of the tree). Therefore, under this model, most extinctions remove only short terminal branches from the tree, and most major lineages survive even extreme pruning of tips. Empirical phylogenies tend to have a very different distribution of branching times (e.g. Rabosky and Lovette 2008; see also Fig. 1b, c for pure birth and birth-death tree). Mooers et al. (2012) explore further how tree shape impacts the expected loss of phylogenetic diversity. The phylogenetic non-random distribution of extinction risk and the shape of empirical phylogenies might therefore suggest that we risk losing a disproportionate amount of evolutionary history from the tree-of-life.

A suite of empirical studies were to follow on from the early work of Nee and May, and emphasized both the phylogenetically non-random nature of species' extinctions and a greater than random loss of phylogenetic diversity (e.g. Purvis et al. 2000a; Purvis 2008; Vamosi and Wilson 2008). A link between non-random 

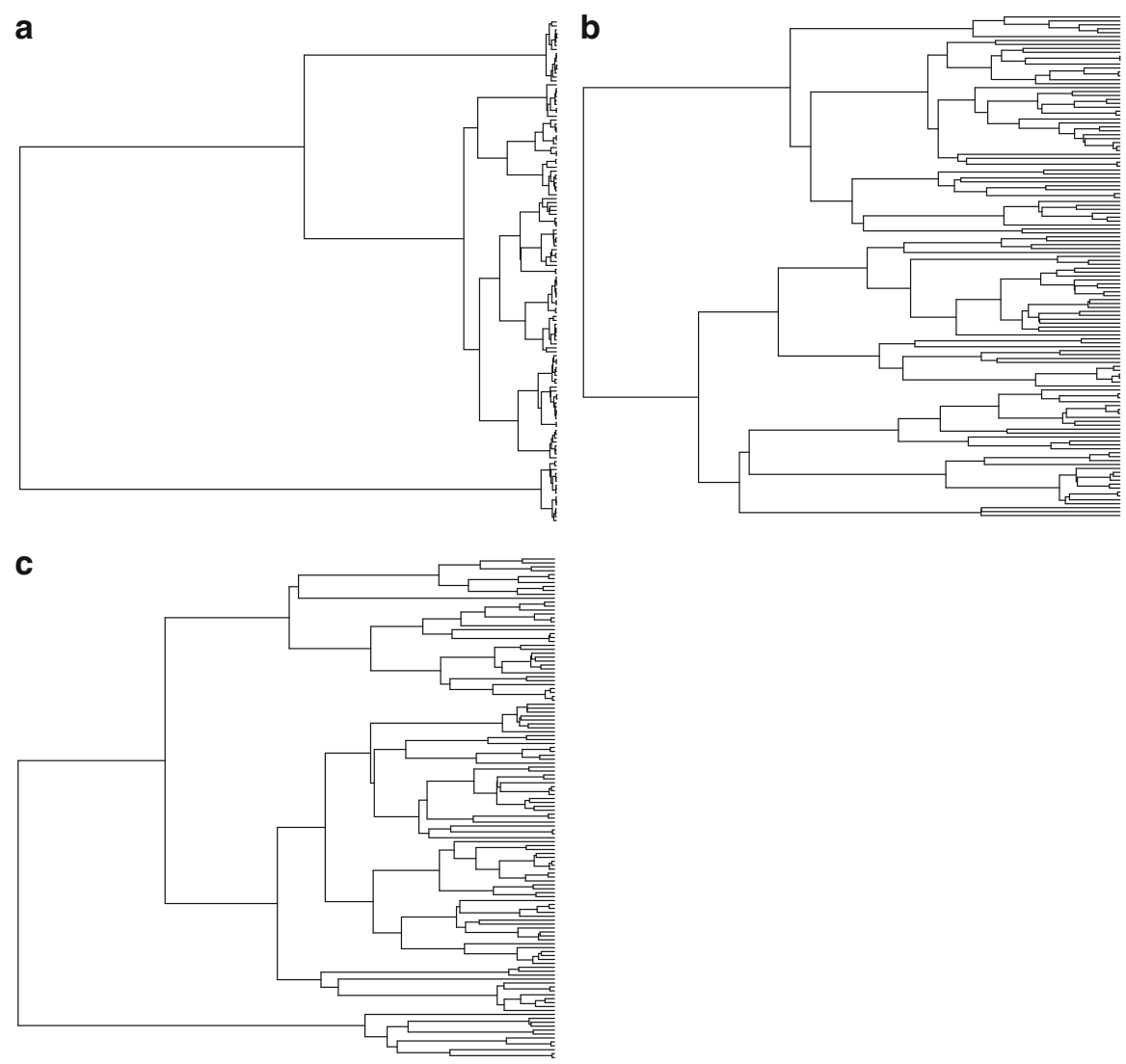

Fig. 1 Comparison of branching times for different tree reconstruction models of size 128 tips. a Coalescent model in which branching clusters towards present; $\mathbf{b}$ pure birth model in which all lineages have an equal probability of splitting $(b=1.0)$ and no lineages go extinct $(d=0)$; $\mathbf{c}$ birthdeath model in which lineages have equal rates of splitting and extinction (birth $=1.0$, death $=0.2$ )

extinction and greater than random loss of phylogenetic diversity seemed intuitive; if two sister species are lost to extinction, not only do we lose the unique phylogenetic diversity captured in the branches from which they subtend, but we also lose the ancestral branch that is shared between them (see Fig. 2). However, in a more recent study, again using simulations, but this time assuming both a more realistic model of diversification and a range of phylogenetic signal in extinction probabilities, Parhar and Mooers (2011) suggested that the loss of phylogenetic diversity under phylogenetically non-random extinctions was more or less indistinguishable from random (see also Heard and Mooers 2000). Seemingly, the observation of phylogenetic signal in extinction risks and the non-random loss of phylogenetic diversity are not necessarily connected directly.

Observations for greater than random losses of phylogenetic diversity that have been inferred for many clades under realistic extinction scenarios likely reflect the 


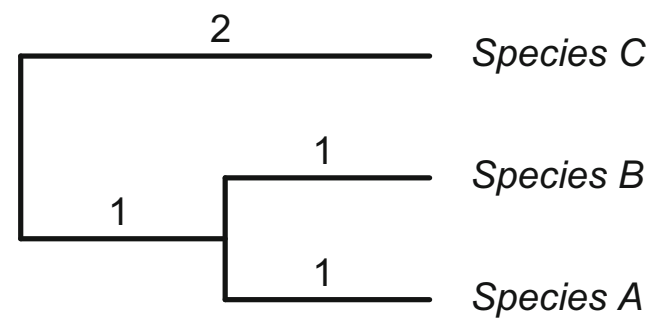

Fig. 2 Ultrametric phylogenetic tree with three tips (A, B and C) and four branches with lengths in millions of years (Myrs). If tip taxa $\mathrm{A}$ and $\mathrm{C}$ become extinct, we lose two branches and 3 Myrs of evolutionary history from the tree. If sister taxa A and B become extinct, for example, because they share a phylogenetically conserved trait that predisposes them to high risk, we also lose 3 Myrs of evolutionary history, but this time three branches are lost from the phylogeny

particularities of phylogenetic tree topology in combination with a tendency for more extinction prone species to fall within species poor clades (Heard and Mooers 2000; von Euler 2001; Parhar and Mooers 2011). There does seem to be a general trend within some clades for threatened species to be overrepresented in speciespoor clades (e.g. in mammals, Purvis et al. 2000b and birds, Bennett and Owens 1997). In plants, patterns appear mixed. As discussed above, there is some evidence suggesting an opposite trend to vertebrates, with a greater proportion of threatened plant species falling within species-rich clades (Schwartz and Simberloff 2001; Lozano and Schwartz 2005), and less evolutionary distinct lineages (Davies et al. 2011). Globally, however, species poor, and especially monotypic plant families, again appear to be more threatened, and their extinction would also result in a disproportionate loss of evolutionary history (Vamosi and Wilson 2008).

\section{Feature Diversity and Evolutionary Models of Character Change}

Underpinning the theoretical arguments for maximizing the preservation of phylogenetic diversity is the assumption that it captures feature diversity (i.e. variance in measured ecological and morphological traits), and thus selecting the set of taxa to maximize phylogenetic diversity will also maximize feature diversity (Faith 1992; Crozier 1997). Many biological traits demonstrate significant phylogenetic signal (Blomberg et al. 2003) and therefore this assumption might be broadly valid. However, the relationship between phylogenetic diversity, which is measured in millions of years, and feature diversity is not straightforward, but assumes a linear divergence between species over time, for example, as might be modeled under a Brownian motion process, in which trait variance increases in proportion with time, but for which evidence is mixed. Frequently, traits demonstrate much weaker phylogenetic signal than assumed by a strict Brownian motion model (e.g. Kamilar and Cooper 2013). Although there are a large number of alternative models of 

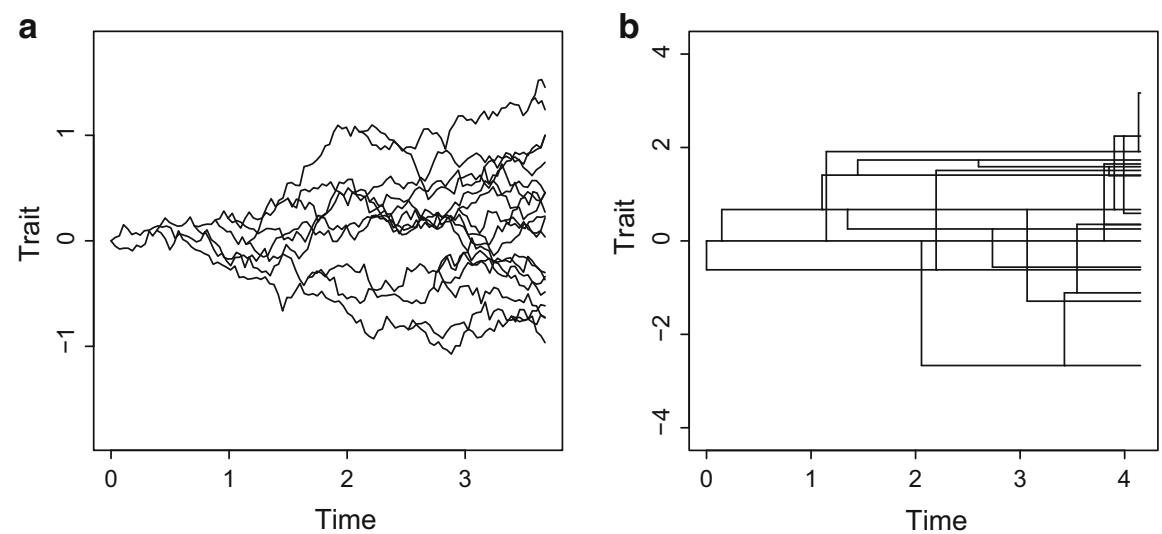

Fig. 3 Simulations showing accumulation of trait variance over time assuming a Brownian motion model of trait evolution $\mathbf{a}$ in which variance increases in proportion to time, versus a punctuated model of trait evolution $\mathbf{b}$ in which trait change occurs in bursts at speciation, and a pure-birth process of phylogenetic branching (see also Ingram 2011; Davies 2015)

evolutionary change, including the Ornstein-Uhlenbeck model which approximates stochastic evolution with stabilizing selection (Hansen 1997) and the early burst model that might characterize adaptive radiations (Harmon et al. 2010), we here (see Davies and Yessoufou 2013; Davies 2015) compare the potential loss of phylogenetic diversity under two models with very different assumptions: (1) a model of phylogenetic gradualism as represented by Brownian Motion (Fig. 3a), and (2) a punctuated model of evolution in which trait differences accumulate in bursts at speciation (Fig. 3b).

To date, the model of evolution has rarely been considered explicitly within the conservation phylogenetics literature (e.g. Owens and Bennett 2000). However, if traits evolve following a speciational model - as may be the case for body mass in mammals (Mattila and Bokma 2008) - where trait evolution occurs in bursts at speciation, each individual branch would capture similar feature diversity, and as such, the number of branches might be of equal, or greater conservation value than their summed lengths. Furthermore, because nonrandom extinction may target deeper branches in the tree-of-life (Mckinney 1997; Purvis et al. 2000a; Purvis 2008), we would predict a disproportionate loss of branches without necessarily a concomitant loss of total summed branch lengths (Fig. 2). Non-random extinction might therefore have a greater impact on number of branches lost than on the sum of their branch lengths - which has been the focus of most studies to date.

Using a dated phylogenetic tree for Primates, Carnivora and Artiodactyla, we (Davies and Yessoufou 2013) combined simulations and empirical extinction risk data from the IUCN Red List of threatened species (http://www.iucnredlist.org/) to explore the loss of phylogenetic diversity under two alternative evolutionary models. First, following standard practice, we calculated the expected loss of PD assuming a gradual model of evolution. Second, we also calculated the equivalent loss of diversity under a speciational model of evolution (in which all branches are assigned 
equal weights) following the approach of Witting and Loeschcke (1995). Extinction categories were first converted into extinction probabilities, p(ext), following Mooers et al. (2008) and assuming IUCN designations projected to 50 years. We then compared observed losses to expectations from the same distribution of $\mathrm{p}(\mathrm{ext})$, but randomly assigned to species at the tips of the phylogeny (100 replicates). Last, we explored the relationship between phylogenetic signal, estimated using Pagel's (1999) Lambda, and the loss of evolutionary history by evolving traits along the branches of simulated phylogenetic trees. Here, we assume a birth-death tree $(b=0.2, d=0$, size $n=240)$, in contrast to the unrealistic coalescent trees used by Nee and May (1997). Based on the simulated trait values, a constant fraction of species (the top $25 \%$, as this broadly matches the proportion of threatened mammal species in the IUCN Red List) were then assigned high risk of extinction $(\mathrm{p}(\mathrm{ext})=0.75)$.

Our results reveal that under a speciational model of evolution, non-random extinction prunes more branches from the tree-of-life (see also Fig. 2), but that the loss of summed branch lengths (Faith's PD) does not depart significantly from random expectation (Davies and Yessoufou 2013). Although there is a weak trend for greater loss of phylogenetic diversity (PD) and number of branches lost with increasing phylogenetic signal in extinction risk, there is large variance in PD loss under random pruning such that observed losses typically overlap to a greater extent with the null distribution. In contrast, there is much less variance in the number of pruned branches such that random extinctions of equivalent intensity would prune similar number of branches. Therefore, observed number of branches loss more often falls outside the null distribution from randomizations (Fig. 4).

\section{Conclusion}

There is an increasing call for prioritizing efforts towards the conservation of phylogenetic diversity (Mace et al. 2003; Forest et al. 2007; Davies et al. 2008). Implicit within this conservation agenda is an assumption that species diverge in their ecological and morphological traits more or less linearly through time, and thus that the evolutionary distance between species captures their functional differences. We (Davies and Yessoufou 2013) explored scenarios where this assumption is violated, and feature diversity occurs in bursts at speciation, matching to a punctuated model of trait evolution. Our results illustrate that projected extinctions might prune more branches from the tree-of-life than predicted from the same number of extinctions randomly distributed across the phylogeny; however, the loss of summed branch length might be no greater than expected by chance.

We do not suggest that punctuated evolution is necessarily a better model of trait change, but rather we emphasise the need for a more explicit consideration of evolutionary models if our aim is to maximize feature diversity. Recent advances in comparative methods have allowed comparisons between alternative evolutionary models, and frequently find strict Brownian motion to be a poor fit to observed trait 


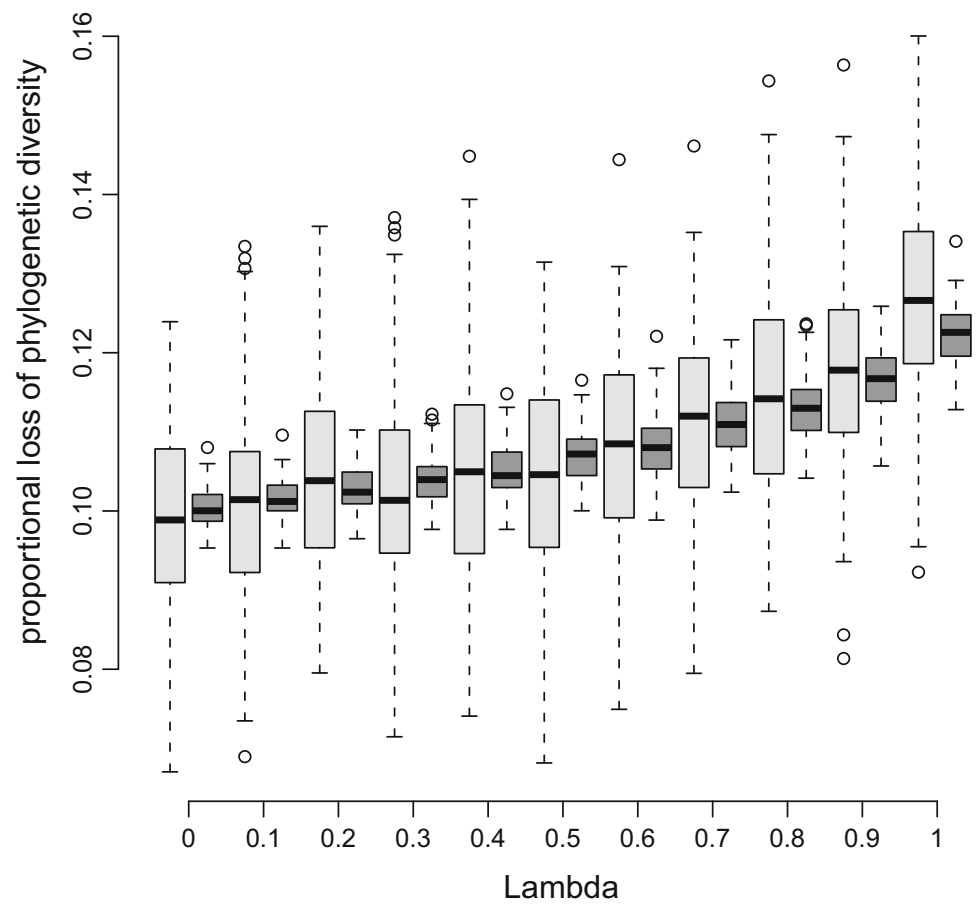

Fig. 4 Results from simulated extinctions with varying levels of phylogenetic clustering (Lambda) across 100 random birth-death trees (see Fig. 1c) assuming p(ext) $=0.75$ for the top $25 \%$ of species. Light grey boxes $=$ expected loss of PD for empirical branch lengths (assuming phylogenetic gradualism or a Brownian motion model of trait change); dark grey boxes $=$ expected loss of PD assuming equal branch lengths (matching to a punctuated model of trait change). Simulations with Lambda $=0$ are equivalent to random extinctions. This figure is similar to that in Davies and Yessoufou (2013), but presents a new set of stochastic simulations

data (e.g. Blomberg et al. 2003; O’Meara et al. 2006; Harmon et al. 2010). It remains possible that Brownian motion might still best capture aggregate species differences even when individual traits diverge from a Brownian motion model, assuming traits are evolving independently or when selective regimes fluctuate over time (Felsenstein 1988). However, this expectation has rarely been evaluated using empirical data.

Finally, we note that our understanding of the distribution of phylogenetic diversity across space and among communities might also be informed by further consideration of evolutionary models. For example, traditional metrics of phylogenetic diversity tend to correlate very closely with species richness (Rodrigues et al. 2005), although it is possible to identify regions of greater or lower phylogenetic diversity than predicted from species richness alone, for example, by looking at residual variation (e.g. Forest et al. 2007; Davies et al. 2008). The covariation between evolutionary history and species richness might exhibit very different properties under alternative evolutionary models, but as far as we are aware, there have not yet been any equivalent studies exploring such models in geographical space. 
Open Access This chapter is distributed under the terms of the Creative Commons AttributionNoncommercial 2.5 License (http://creativecommons.org/licenses/by-nc/2.5/) which permits any noncommercial use, distribution, and reproduction in any medium, provided the original author(s) and source are credited.

The images or other third party material in this chapter are included in the work's Creative Commons license, unless indicated otherwise in the credit line; if such material is not included in the work's Creative Commons license and the respective action is not permitted by statutory regulation, users will need to obtain permission from the license holder to duplicate, adapt or reproduce the material.

\section{References}

Achard F, Eva HD, Stibig HJ, Mayaux P, Gallego J, Richards T, Malingreau JP (2002) Determination of deforestation rates of the world's humid tropical forests. Science 297:999-1002

Ashley MV, Wilson MF, Pergams ORW, O’Dowd DJ, Gende SM, Brown JS (2003) Evolutionarily enlightened management. Biol Conserv 111:115-123

Baillie JEM, Hilton-Taylor C, Stuart SN (2004) A global species assessment. IUCN, Gland, Switzerland

Barraclough TG, Davies TJ (2005) Predicting future speciation. In: Purvis A, Gittleman JL, Brooks T (eds) Phylogeny and conservation. Cambridge University Press, Cambridge, pp 400-418

Barraclough TG, Vogler AP (2002) Recent diversification rates in North American tiger beetles estimated from a dated mtDNA phylogenetic tree. Mol Biol Evol 19:1706-1716

Barraclough TG, Nee S, Harvey PH (1998) Sister-group analysis in identifying correlates of diversification - comment. Evol Ecol 12:751-754

Bennett PM, Owens IPF (1997) Variation in extinction risk among birds: chance or evolutionary predisposition. Proc R Soc Lond B 264:401-408

Benton MJ, Emerson BC (2007) How did life become so diverse? The dynamics of diversification according to the fossil record and molecular phylogenetics. Palaeontology 50:23-40

Bininda-Emonds ORP, Cardillo M, Jones KE, MacPhee RDE, Beck RMD, Grenyer R, Price SA, Vos RA, Gittleman JL, Purvis A (2007) The delayed rise of present-day mammals. Nature 446:507-512

Blomberg SP, Garland T, Ives AR (2003) Testing for phylogenetic signal in comparative data: behavioral traits are more labile. Evolution 57:717-745

Bodmer RE, Eisenberg JF, Redford KH (1997) Hunting and the likelihood of extinction of Amazonian mammals. Conserv Biol 11:460-466

Bradshaw CJA, Giam X, Tan HTW, Brook BW, Sodhi NS (2008) Threat or invasive status in legumes is related to opposite extremes of the same ecological and life history attributes. J Ecol 96:869-883

Brook BW, Sodhi NS, Bradshaw CJA (2008) Synergies among extinction drivers under global change. Trends Ecol Evol 23:453-460

Butchart SHM, Stattersfield AJ, Bennun LA, Shutes SM, Akcakaya HR, Baillie JEM, Stuart SN (2004) Measuring global trends in the status of biodiversity: red list indices for birds. PLoS Biol 2:e383

Cardillo M (2003) Biological determinants of extinction risk: why are smaller species less vulnerable? Anim Conserv 6:63-69

Cardillo M, Bromham L (2001) Body size and risk of extinction in Australian mammals. Conserv Biol 15:1435-1440

Cardillo M, Meijaard E (2012) Are comparative studies of extinction risk useful for conservation? Trends Ecol Evol 27:167-171 
Cardillo M, Mace GM, Jones KE, Bielby J, Bininda-Emonds ORP, Sechrest W, Orme CDL, Purvis A (2005) Multiple causes of high extinction risk in large mammal species. Sciences 309:1239-1241

Cardillo M, Mace GM, Gittleman JL, Purvis A (2006) Latent extinction risk and the future battlegrounds of mammal conservation. Proc Natl Acad Sci U S A 103:4157-4161

Cardillo M, Mace GM, Gittleman JL, Jones KE, Bielby J, Purvis A (2008) The predictability of extinction: biological and external correlates of decline in mammals. Proc R Soc B 275:1441-1448

Cione AL, Tonni EP, Soibelzon L (2003) The Broken zig-zag: late Cenozoic large mammal and tortoise extinction in South America. Rev Mus Argent Cienc Nat 5:1-19

Collen B, Böhm M, Kemp R, Baillie JEM (2012) Spineless: status and trends of the world's invertebrates. Zoological Society of London, London. ISBN 978-0-900881-68-8

Cooper N, Bielby J, Thomas HG, Purvis A (2008) Macroecology and extinction risk correlates of frogs. Glob Ecol Biogeogr 17:211-221

Crisp MD, Cook LG (2009) Explosive radiation or cryptic mass extinction? Interpreting signatures in molecular phylogenies. Evolution 63:2257-2265

Crozier RH (1997) Preserving the information content of species: genetic diversity, phylogeny, and conservation worth. Annu Rev Ecol Syst 28:243-268

Damuth J (1981) Population density and body size in mammals. Nature 290:699-700

Daru BH, Yessoufou K, Mankga LT, Davies TJ (2013) A global trend towards the loss of evolutionarily unique species in mangrove ecosystems. PLoS One 8(6):e66686

Davies TJ (2015) Losing history: how extinctions prune features from the tree-of-life. Philos Trans R Soc B 370. doi:10.1098/rstb.2014.0006

Davies TJ, Cadotte MW (2011) Quantifying biodiversity - does it matter what we measure? In: Zachos FE, Habel JC (eds) Biodiversity hotspots. Springer, Heidelberg, pp 43-60

Davies TJ, Yessoufou K (2013) Revisiting the impacts of non-random extinction on the tree-of-life. Biol Lett 9:20130343

Davies TJ, Barraclough TG, Chase MW, Soltis PS, Soltis DE, Savolainen V (2004) Darwin's abominable mystery: insights from a supertree of the angiosperms. Proc Natl Acad Sci U S A 101:1904-1909

Davies TJ, Fritz SA, Grenyer R, Orme CD, Bielby J, Bininda-Edmonds OR, Cardillo M, Jones KE, Gittleman JL, Mace GM, Purvis A (2008) Phylogenetic trees and the future of mammalian biodiversity. Proc Natl Acad Sci USA 105:11556-11563

Davies TJ, Smith GF, Bellstedt DU, Boatwright JS, Bytebier B, Cowling RM, Forest F, Harmon LJ, Muasya AM, Schrire BD, Steenkam Y, Van der Bank M, Savolainen V (2011) Extinction risk and diversification are linked in a plant biodiversity hotspot. PLoS Biol 9:e1000620

Davies TJ, Wolkovich EM, Kraft NJB, Salamin N, Allen JM, Ault TR, Betancourt JL, Bolmgren K, Cleland EE, Cook BI, Crimmins TM, Mazer SJ, McCabe GJ, Pau S, Regetz J, Schwartz MD, Travers SE (2013) Phylogenetic conservatism in plant phenology. J Ecol 101:1520-1530

Diamond J (1984) Normal extinctions of isolated populations. In: Nitecki MH (ed) Extinctions. University of Chicago Press, Chicago, pp 191-246

Diamond J (1989) Overview of recent extinctions. In: Pearl M, Western D (eds) Conservation for the twenty-first century. Oxford University Press, New York, pp 37-41

Dirzo R, Raven PJ (2003) Global state of biodiversity and loss. Annu Rev Environ Resour 28:137-167

Endler JA (1986) Natural selection in the wild. Princeton University Press, Princeton, USA

Faith DP (1992) Conservation evaluation and phylogenetic diversity. Biol Conserv 61:1-10

Faith DP (2002) Quantifying biodiversity: a phylogenetic diversity. Conserv Biol 16:248-252

Faith DP (2008) Threatened species and the potential loss of phylogenetic diversity: conservation scenarios based on estimated extinction probabilities and phylogenetic risk analysis. Conserv Biol 22:1461-1470

Faith DP, Magallón S, Hendry AP, Conti E, Yahara T, Donoghue MJ (2010) Evosystem services: an evolutionary perspective on the links between biodiversity and human well-being. Curr Opin Environ Sustain 2:66-74 
Felsenstein J (1985) Phylogenies and the comparative methods. Am Nat 125:1-15

Felsenstein J (1988) Phylogenies and quantitative characters. Annu Rev Ecol Syst 19:445-471

Fenschel T (1974) Intrinsic rate of natural increase: the relationship with body size. Oecologia 14:317-332

Fisher DO, Owens IPF (2004) The comparative method in conservation biology. Trends Ecol Evol 19:391-398

Forest F, Grenyer R, Rouget M, Davies J, Cowling RM, Faith DP, Balmford A, Manning JC, Proches S, Van der Bank M, Reeves G, Hedderson TAJ, Savolainen V (2007) Preserving the evolutionary potential of floras in biodiversity hotspots. Nature 445:757-760

Freville H, McConway K, Dodd M, Silvertown J (2007) Prediction of extinction in plants: interactions of extrinsic threats and life history traits. Ecology 88:2662-2672

Fritz SA, Purvis A (2010) Selectivity in mammalian extinction risk and threat types: a new measure of phylogenetic signal strength in binary traits. Conserv Biol 24:1042-1051

Gavrilets S, Vose A (2005) Dynamic patterns of adaptive radiation. Proc Natl Acad Sci U S A 102:18040-18045

Goldberg EM, Lancaster LT, Ree RH (2011) Phylogenetic inference of reciprocal effects between geographic range evolution and diversification. Syst Biol 60:451-465

Grandcolas P, Nattier R, Legendre F, Pellens R (2011) Mapping extrinsic traits such as extinction risks or modelled bioclimatic niches on phylogenies: does it make sense at all? Cladistics 27:181-185

Grenyer R, Orme CDL, Jackson SF, Thomas GH, Davies RG, Davies TG, Jones KE, Olson VA, Ridgely RS, Rasmussen PC, Ding T-S, Bennett PM, Blackburn TM, Gaston KJ, Gittleman JL, Owens IPF (2006) Global distribution and conservation of rare and threatened vertebrates. Nature 444:93-96

Haberl H, Erb KH, Krausmann F, Gaube V, Bondeau A, Plutzar C, Gingrich S, Lucht W, FischerKowalski M (2007) Quantifying and mapping the human appropriation of net primary production in earth's terrestrial ecosystems. Proc Natl Acad Sci U S A 104:12942-12947

Hansen TF (1997) Stabilizing selection and the comparative analysis of adaptation. Evolution 51:1341-1351

Harmon LJ, Schulte JA, Larson A, Losos JB (2003) Tempo and model of evolutionary radiation in iguanian lizards. Science 301:961-964

Harmon LJ, Losos JB, Davies TJ, Gillepsie RG, Gittleman JL, Jennings WB, Kozak KH, McPeek MA, Moreno-Roark F, Near TJ, Purvis A, Ricklefs RE, Dolph S, Schulte JA II, Seehausen O, Sidlauskas BL, Torres-Carvajal O, Weir JT, Mooers AO (2010) Early bursts of body size and shape evolution are rare in comparative data. Evolution 64:2385-2396

Harvey PH, May RM, Nee S (1994) Phylogenies without fossils. Evolution 48:523-529

Heard SB, Mooers AO (2000) Phylogenetically patterned speciation rates and extinction risks change the loss of evolutionary history during extinctions. Proc R Soc Lond B 267:613-620

Hooper DU, Adair EC, Cardinale BJ, Byrnes JEK, Hungate BA, Matulich KL, Gonzalez A, Duffy EJ, Gamfeldt L, O’Connor MI (2012) A global synthesis reveals biodiversity loss as a major driver of ecosystem change. Nature 486:105-108

Huang S, Gittleman JG, Davies TJ (2012) How global extinctions impact regional biodiversity in mammals. Biol Lett 8:222-225

Ingram T (2011) Speciation along a depth gradient in a marine adaptive radiation. Proc R Soc B 278:613-618

Isaac NJB, Turvey ST, Collen B, Waterman C, Baillie JEM (2007) Mammals on the EDGE: conservation priorities based on threat and phylogeny. PLoS One 2:e296

Isaac NJB, Redding DW, Meredith HM, Safi K (2012) Phylogenetically-informed priorities for amphibian conservation. PLoS One 7:e43912

IUCN (2003) IUCN red list of threatened species. IUCN, Gland, Switzerland

IUCN (2010) IUCN sampled red list index for plants. http://www.kew.org/science-conservation/ kew-biodiversity/plants-at-risk/indexhtm.

Jablonski D (1995) Extinctions in the fossil record. In: Lawton JH, May RM (eds) Extinction rates. Oxford University Press, Oxford, pp 25-44 
Jansson R, Davies TJ (2008) Global variation in diversification rates of flowering plants: energy versus climate change. Ecol Lett 11:173-183

Jerozolimski A, Peres CA (2003) Bringing home the biggest bacon: a cross-site analysis of the structure of hunter-kill profiles in neotropical forests. Biol Conserv 111:415-425

Johnson CN (2002) Determinants of loss of mammal species during the late Quaternary "megafauna" extinction: life history and ecology, but not body size. Proc R Soc B 269:2221-2228

Jones DL (2002) Cycads of the world: ancient plants in today's landscape. Smithsonian Institution Press, Washington, DC

Kadereit JW, Greibler EM, Comes HP (2004) Quaternary diversification in European alpine plants: pattern and process. Philos Trans R Soc B 359:265-274

Kamilar JM, Cooper N (2013) Phylogenetic signal in primate behaviour, ecology and life history. Philos Trans R Soc B 368:20120341

Kettlewell MG (1972) The evolution of melanism. Oxford University Press, Oxford

Kinnison MT, Hendry AP (2001) The pace of modern life II: from rates of contemporary microevolution to pattern and process. Genetica 112:145-164

Kozak KH, Weisrock DW, Larson A (2006) Rapid lineage accumulation in a non-adaptive radiation: phylogenetic analysis of diversification rates in eastern North American woodland salamanders (Plethodontidae: Plethodon). Proc R Soc B 273:539-546

Laurance WF (1991) Ecological correlates of extinction proneness in Australian tropical rainforest mammals. Conserv Biol 5:79-89

Lawton JH (1995) Population dynamic principles. In: Lawton JH, May RM (eds) Extinction rates. Oxford University Press, Oxford, pp 147-163

Linder HP, Eldenäs P, Briggs BG (2003) Contrasting patterns of radiation in African and Australian Restionaceae. Evolution 57:2688-2702

Lohle C, Eschenbach W (2011) Historical bird and terrestrial mammal extinction rates and causes. Divers Distrib 18:84-91

Lozano FD, Schwartz MW (2005) Patterns of rarity and taxonomic group size in plants. Biol Conserv 126:146-154

MacArthur RH, Wilson EO (1963) An equilibrium theory of insular zoogeography. Evolution 17:373-387

MacArthur RH, Wilson EO (1967) The theory of island biogeography. Princeton University Press, Princeton, USA

Mace GM, Gittleman JL, Purvis A (2003) Preserving the tree of life. Science 300:1707-1709

Mace G, Masundire H, Baillie JEM (2005a) Biodiversity. In: Hassan R, Scholes R, Ash N (eds) Ecosystems and human well-being: current state and trends: findings of the condition and trends working group. Island Press, Washington, DC, pp 77-122

Mace GM, Baillie JEM, Masundire H, Ricketts TH, Brooks TM et al (2005b). Biodiversity. In: The millennium ecosystem assessment: current status and trends: findings of the conditions and trends working group. Ecosystems and human well-being. Island Press, Washington, DC, pp 53-98

Machordom A, Macpherson E (2004) Rapid radiation and cryptic speciation in squat lobsters of the genus Munida (Crustacea, Decapoda) and related genera in the southwest Pacific: molecular and morphological evidence. Mol Phylogenet Evol 33:259-279

Maddison WP, Midford PE, Otto SP (2007) Estimating a binary character's effect on speciation and extinction. Syst Biol 56:701-710

Martin PS (1967) Prehistoric overkill. In: Martin PS, Wright HE (eds) Pleistocene extinctions: the search for a cause. Yale University Press, New Haven, pp 75-120

Mattila TM, Bokma F (2008) Extant mammal body masses suggest punctuated equilibrium. Proc R Soc B 275:2195-2199

May RM (2010) Tropical arthropod species, more or less? Science 329(5987):41-42

May RM, Lawton JH, Stork NE (1995) Assessing extinction rates. In: Lawton JH, May RM (eds) Extinction rates. Oxford University Press, Oxford, pp 1-24

McCormack JE, Harvey MG, Faircloth BC, Crawford NG, Glenn TC, Brumfield RT (2013) A phylogeny of birds based on over 1500 loci collected by target enrichment and high-throughput sequencing. PLoS One 8:e54848 
McKinney ML (1997) Extinction vulnerability and selectivity: combining ecological and paleontological views. Annu Rev Ecol Syst 28:495-516

Meijaard E, Sheil D, Marshall J, Nasi R (2007) Phylogenetic age is positively correlated with sensitivity to timber harvest in Bornean mammals. Biotropica 40:76-85

Millennium Ecosystem Assessment (2005) Ecosystems and human well-being: synthesis. Island Press, Washington, DC, $137 \mathrm{pp}$

Mooers AØ, Heard SB, Chrostowski E (2005) Evolutionary heritage as a metric for conservation. In: Purvis A, Brooks TL, Gittleman JL (eds) Phylogeny and conservation. Oxford University Press, Oxford, pp 120-138

Mooers AØ, Faith DP, Maddison WP (2008) Converting endangered species categories to probabilities of extinction for phylogenetic conservation prioritization. PLoS One 3:e3700

Mooers A, Gascuel O, Stadler T, Li H, Steel M (2012) Branch lengths on birth-death trees and the expected loss of phylogenetic diversity. Syst Biol 61:195-203

Mora C, Tittensor DP, Adl S, Simpson AGB, Worm B (2011) How many species are there on Earth and in the ocean? PLoS Biol 9:e1001127

Morrison CL, Rios R, Duffy JE (2004) Phylogenetic evidence for an ancient rapid radiation of Caribbean sponge-dwelling snapping shrimps (Synalpheus). Mol Phylogenet Evol 30:563-581

Nee S (2006) Birth-death models in macroevolution. Annu Rev Ecol Syst 37:1-17

Nee S, May RM (1997) Extinction and the loss of evolutionary history. Science 278:692-694

Nee S, Holmes EC, May RM, Harvey PH (1994) Extinction rates can be estimated from molecular phylogenies. Proc R Soc Lond B 344:77-82

Niklas KJ (1997) The evolutionary biology of plants. University of Chicago Press, Chicago

O'Meara BC, Ane' C, Sanderson MJ, Wainwright PC (2006) Testing for different rates of continuous trait evolution using likelihood. Evolution 60:922-933

Orme CDL, Davies RG, Burgess M, Eigenbrod F, Pickup N, Olson VA, Webster AJ, Ding T-S, Rasmussen PC, Ridgely RS, Stattersfield AJ, Bennett PM, Blackburn TM, Gaston KJ, Owens IPF (2005) Global hotspots of species richness are not congruent with endemism or threat. Nature 436:1016-1019

Owens IPF, Bennett PM (2000) Quantifying biodiversity: a phenotypic perspective. Conserv Biol 14:1014-1022

Pagel M (1999) Inferring the historical patterns of biological evolution. Nature 401:877-884

Parhar RK, Mooers AØ (2011) Phylogenetically clustered extinction risks do not substantially prune the tree of life. PLoS One 6:e23528

Parmesan C (2007) Influences of species, latitudes and methodologies on estimates of phenological response to global warming. Glob Chang Biol 13:1860-1872

Phillimore AB, Price TD (2008) Density-dependent cladogenesis in birds. PLoS Biol 6:e71

Pilgrim ES, Crawley MJ, Dolphin K (2004) Patterns of rarity in the native British flora. Biol Conserv 120:161-170

Pimm SL (1991) The balance of nature? University of Chicago Press, Chicago

Pimm SL, Jones HL, Diamond J (1988) On the risk of extinction. Am Nat 132:757-785

Pimm SL, Russell GJ, Gittleman JL, Brooks TM (1995) The future of biodiversity. Science 269:347-350

Purcell SW, Polidoro BA, Hamel J-F, Gamboa RU, Mercier A (2014) The cost of being valuable: predictors of extinction risk in marine invertebrates exploited as luxury seafood. Proc R Soc B 281:20133296

Purvis A (2008) Phylogenetic approaches to the study of extinction. Annu Rev Ecol Evol Syst 39:301-319

Purvis A, Agapow PM, Gittleman JL, Mace GM (2000a) Nonrandom extinction and the loss of evolutionary history. Science 288:328-330

Purvis A, Gittleman JL, Cowlishaw G, Mace GM (2000b) Predicting extinction risk in declining species. Proc R Soc Lond B 267:1947-1952 
Purvis A, Gittleman JL, Brooks TM (2005) Phylogeny and conservation. Cambridge University Press, Cambridge

Pyron RA, Wiens JJ (2013) Large-scale phylogenetic analyses reveal the causes of high tropical amphibian diversity. Proc R Soc B 280:20131622

Rabosky DL (2010) Extinction rates should not be estimated from molecular phylogenies. Evolution 64-6:1816-1824

Rabosky DL, Lovette IJ (2008) Explosive evolutionary radiations: increasing extinction or decreasing speciation through time? Evolution 62:1866-1875

Raup DM (1986) Biological extinction in Earth history. Science 231:1528-1533

Raup D (1991) Extinction: bad genes or bad luck? New Sci 131:46-49

Raup DM (1993) Extinction: bad genes or bad luck? Oxford University Press, Oxford

Ricklefs RE, Bermingham E (2002) The concept of the taxon cycle in biogeography. Glob Ecol Biogeogr 11:353-361

Rodrigues ASL, Brooks TM, Gaston KJ (2005) Integrating phylogenetic diversity in the selection of priority areas for conservation: does it make a difference? In: Purvis A, Gittleman JL, Brooks T (eds) Phylogeny and conservation. Cambridge University Press, Cambridge, pp 101-119

Rolland J, Condamine FL, Jiquet F, Morlon H (2014) Faster speciation and reduced extinction in the tropics contribute to the mammalian latitudinal diversity gradient. PLoS Biol 12:e1001775

Russell GJ, Brooks TM, McKinney MM, Anderson CG (1998) Present and future taxonomic selectivity in birds and mammal extinctions. Conserv Biol 12:1365-1376

Sandel B, Arge L, Dalsgaard B, Davies RG, Gaston KJ, Sutherland WJ, Svenning J-C (2011) The influence of late quaternary climate-change velocity on species endemism. Science 334:660-664

Saslis-Lagoudakis, CH, Kligard, BB, Forest F, Francis L, Savolainen V, Williamson EM, Hawkins JA (2011) The use of phylogeny to interpret cross-cultural patterns in plant use and guide medicinal plant discovery: an example from Pterocarpus (Leguminosae). PloS ONE6(7):e22275

Scantlebury DP (2013) Diversification rates have declined in the Malagasy herpetofauna. Proc R Soc B 280:20131109

Schluter D (2000) The ecology of adaptive radiation. Oxford University Press, Oxford

Schwartz MW, Simberloff D (2001) Taxon size predicts rarity in vascular plants. Ecol Lett 4:464-469

Seehaussen O (2006) Conservation: losing biodiversity by reverse speciation. Curr Biol 9:R334-R337

Shaw AJ, Cox CJ, Goffinet B, Buck WR, Boles SB (2003) Phylogenetic evidence of a rapid radiation of pleurocarpous mosses (Bryophyta). Evolution 57:2226-2241

Simpson G (1953) The major features of evolution. Columbia University Press, New York, $434 \mathrm{p}$

Sodhi NS, Brook BW (2006) Southeast Asian biodiversity in crisis. Cambridge University Press, Cambridge

Sodhi NS, Koh LP, Peh KS-H, Tan HTW, Chazdon RL, Corlett RT, Lee TM, Colwell RK, Brook BW, Sekercioglu CH, Bradshaw CJA (2008) Correlates of extinction proneness in tropical angiosperms. Divers Distrib 14:1-10

Srivastava DS, Cadotte MW, MacDonald AAM, Marushia RG, Mirotchnick N (2012) Phylogenetic diversity and the functioning of ecosystems. Ecol Lett 15:637-648

Stuart SN, Chanson JS, Cox NA, Young BE, Rodrigues ASL, Fischman DL, Waller RW (2004) Status and trends of amphibian declines and extinctions worldwide. Science 306:1783-1786

Taylor TN, Taylor EL, Krings M (2009) Paleobotany: the biology and evolution of fossil plants. Academic, Burlington

Thomas CD, Cameroon A, Green RE, Bakkenes M, Beaumont LJ, Collingham YC, Erasmus BF, De Siqueira MF, Grainger A, Hannah L, Hughes L, Huntley B, Van Jaarsveld AS, Midgley GF, Miles L, Ortega-Huerta MA, Peterson AT, Phillips OL, Williams SE (2004) Extinction risk from climate change. Nature 427:145-148

Turgeon J, Stoks R, Thum RA, Brown JM, McPeek MA (2005) Simultaneous quaternary radiations of three damselfly clades across the Holarctic. Am Nat 165:E78-E107 
Vamosi JC, Vamosi SM (2008) Extinction risk escalates in the tropics. PLoS One 3:e3886

Vamosi JC, Wilson JRU (2008) Nonrandom extinction leads to elevated loss of angiosperm evolutionary history. Ecol Lett 11:1047-1053

Verde Arregoita LD, Blomberg SP, Fischer DO (2013) Phylogenetic correlates of extinction risk in mammals: species in older lineages are not at greater risk. Proc R Soc B 280:20131092

Vitousek PM, Mooney HA, Lubchenco J, Melillo JM (1997) Human domination of earth's ecosystems. Science 277:494-499

Von Euler F (2001) Selective extinction and rapid loss of evolutionary history in the bird fauna. Proc R Soc B 268:127-130

Wake DB, Vredenburg VT (2008) Are we in the midst of the sixth mass extinction ? A view from the world of amphibians. Proc Natl Acad Sci U S A 105:11466-11473

Walker KJ, Preston CD (2006) Ecological predictors of extinction risk in the flora of lowland England, UK. Biodivers Conserv 15:1913-1942

Weir J (2006) Divergent timing and patterns of species accumulation in lowland and highland Neotropical birds. Evolution 60:842-855

Williams ST, Reid DG (2004) Speciation and diversity on tropical rocky shores: a global phylogeny of snails of the genus Echinolittorina. Evolution 58:2227-2251

Willis CG, Ruhfel B, Primack RB, Miller-Rushing AJ, Davis CC (2008) Phylogenetic patterns of species loss in Thoreau's woods are driven by climate change. Proc Natl Acad Sci U S A 105:17029-17033

Willis CG, Ruhfel BR, Primack RB, Miller-Rushing AJ, Losos JB, Davis CC (2010) Favourable climate change response explains non-native species' success in Thoreau's Woods. PLoS One 5:e8878

Wilson EO (1961) The nature of the taxon cycle in the Melanesian ant fauna. Am Nat 95:169-193

Wilson EO (1992) The diversity of life. Norton WW \& Co, New York

Winter M, Schweigera O, Klotza S, Nentwigc W, Andriopoulos P, Arianoutsou M, Basnou C, Delipetrou P, Didžiulis V, Hejda M, Hulme PE, Lambdon PW, Pergl J, Pyšek P, Roy DB, Kühn I (2009) Plant extinctions and introductions lead to phylogenetic and taxonomic homogenization of the European flora. Proc Natl Acad Sci U S A 106:21721-21725

Winter M, Vincent D, Oliver S (2013) Phylogenetic diversity and nature conservation: where are we? Trends Ecol Evol 28:199-204

Witting L, Loeschcke V (1995) The optimization of biodiversity conservation. Biol Conserv 71:205-207

Wright SJ (2005) Tropical forests in a changing environment. Trends Ecol Evol 20:553-560

Xiang Q-Y, Manchester SR, Thoma DT, Zhang W, Fan C (2005) Phylogeny, biogeography, and molecular dating of cornelian cherries (Cornus, Cornaceae): tracking tertiary plant migration. Evolution 59:1685-1700

Yessoufou K, Daru BH, Davies TJ (2012) Phylogenetic patterns of extinction risk in the eastern arc ecosystems, an African biodiversity hotspot. PLoS One 7:e47082

Yessoufou K, Bamigboye SO, Daru BH, Van der Bank M (2014) Evidence of constant diversification punctuated by a mass extinction in the African cycads. Ecol Evol 4:50-58

Zhang Y-B, Ma K-P (2008) Geographic distribution patterns and status assessment of threatened species in China. Biodivers Conserv 17:1783-1798 